OPEN ACCESS

Edited by:

Danny Horesh,

Bar-Ilan University, Israel

Reviewed by:

Jennifer Kennel,

Universitätsklinikum des Saarlandes,

Germany

Yang Zhang,

Soochow University, China

*Correspondence:

Marek S. Kopacz

marek.kopacz@va.gov

Specialty section:

This article was submitted to

Psychopathology,

a section of the journal

Frontiers in Psychiatry

Received: 28 March 2018

Accepted: 13 August 2018 Published: 04 September 2018

Citation:

Kopacz MS, Ames D and Koenig HG (2018) Association Between Trust and

Mental, Social, and Physical Health

Outcomes in Veterans and Active Duty

Service Members With

Combat-Related PTSD

Symptomatology

Front. Psychiatry 9:408

doi: 10.3389/fpsyt.2018.00408

\section{Association Between Trust and Mental, Social, and Physical Health Outcomes in Veterans and Active Duty Service Members With Combat-Related PTSD Symptomatology}

\author{
Marek S. Kopacz ${ }^{1,2 *}$, Donna Ames ${ }^{3,4}$ and Harold G. Koenig ${ }^{5,6,7}$ \\ ${ }^{1}$ VISN 2 Center of Excellence for Suicide Prevention, U.S. Department of Veterans Affairs, Canandaigua, NY, United States, \\ ${ }^{2}$ Mental Health and Chaplaincy, U.S. Department of Veterans Affairs, Durham, NC, United States, ${ }^{3}$ VA Greater Los Angeles \\ Healthcare System, Los Angeles, CA, United States, ${ }^{4}$ David Geffen School of Medicine, University of California, Los Angeles, \\ Los Angeles, CA, United States, ${ }^{5}$ Department of Psychiatry \& Behavioral Sciences, Duke University Medical Center, Durham, \\ NC, United States, ${ }^{6}$ Department of Medicine, King Abdulaziz University, Jeddah, Saudi Arabia, ${ }^{7}$ School of Public Health, \\ Ningxia Medical University, Yinchuan, China
}

Background: Trust represents a complex emotion and interpersonal concept which assumes abandoning control over a given situation or set of circumstances, in turn yielding such control to another party. Advances in our knowledge of post-traumatic stress disorder and moral injury have underscored the need to more closely examine how trust stands to impact health outcomes in these disorders. The aim of the present study is to examine and identify relationships linking general trust with select health outcomes in a mixed sample of Veterans and Service members with a self-reported history of deployment to a combat theater and PTSD symptomatology.

Methods: This study applied a cross-sectional methodology, surveying $n=427$ participants recruited across six sites. This included 373 Veterans and 54 active duty Service members in the United States. Measures included demographic characteristics, combat exposure, general trust, post-traumatic stress disorder symptomatology, depressive/anxiety symptomatology, alcohol use, social involvement, religiosity, and physical health. Data were analyzed descriptively as well as using Pearson correlations, Student's $t$-test, and multivariate regression.

Results: Several significant relationships were identified, indicating an inverse relationship between trust and PTSD, depressive, and anxiety symptomatology. Greater levels of trust were also significantly associated with increased social interaction and religiosity. Lastly, no significant associations were identified with either physical functioning or pain level.

Conclusion: The findings suggest that trust is correlated with a variety of health outcomes in Veterans and Service members affected by combat-related PTSD. 
Additional, hypothesis-driven research, informed by longitudinal data, is needed to better understand how trust stands to impact health outcomes, including the development of strategies and intervention options for repairing trust.

Keywords: trust, post-traumatic stress disorder, Veterans, active duty military, depression, anxiety, pain, physical function

\section{INTRODUCTION}

Developing and establishing trusting relationships remains essential to healthy human development. Trust represents a complex emotion and interpersonal concept which assumes abandoning control over a given situation or set of circumstances, in turn yielding such control to another party (1). An enhanced or diminished capacity for trust stands to tangibly impact individual well-being across the biological-psychological-social spectrum (2). Of note, however, is that only a limited literature has informed understandings of how disturbed trust stands to impact the health and well-being of Veteran and Service member populations.

The value and importance of trust is especially well developed in the military, where the dynamic of military service pushes the issue of trust to the forefront (3-6). Operationalizing military policies or directives as well as ensuring individual and organizational safety is inherently dependent on trust between Service members to adhere to a common culture of accepted practices, principles, values, beliefs, and behaviors $(7,8)$. Even after military service, the presence or absence of trust remains a key factor in whether some Veterans choose to establish and maintain interpersonal as well as organizational relationships (9). For example, ensuring that Veterans and Service members retain trust in their health care providers is considered to be of critical importance. Trauma from combat experiences in particular has been significantly associated with a variety of adverse mental health outcomes (10-12).

A diminished capacity for trust usually falls under the rubric of general psychopathology and can be indicative of any number of clinical disorders. Understandings of how impacted trust stands to affect the health of Veteran and Service member populations have largely focused on samples affected by post-traumatic stress disorder (PTSD). In general terms, a diminished capacity for trust hampers access to social capital and supportive services, contributing to a downward spiral of increasing social isolation and difficulty accessing vital services (13). These understandings, however, remain limited, highlighting a need to advance our knowledge by more closely examining how trust stands to impact health outcomes in select Veteran and Service member populations.

Disturbed trust is commonly encountered in cases of PTSD (14). Disturbed trust has been cited as a reason why some Veterans do not engage in health care services $(15,16)$ or feel uncomfortable with available treatment options $(17,18)$. Disturbed trust also affects such domains as relationship functioning (19) and experiences of spirituality/religion (20). Of note is that differences have been noted in clinical presentation, pathophysiology, therapeutic responsiveness, and screening sensitivity and specificity between combat-related and non-combat-related PTSD (21-23). Such differences arguably suggest that those affected by combat-related PTSD may have unique health care needs reflective of their impacted trust. Interestingly, no published data appears to be available directly examining experiences of trust, or any health implications thereof, in populations specifically affected by combat-related PTSD. Depending on the study population, the prevalence of combat-related PTSD among American Veterans is thought to range from 2 to $17 \%$ (24).

An emerging body of research into moral injury (MI) has also informed understandings of trust among Veterans and Service members. There is presently no clinical threshold or diagnostic standard to identify cases of MI. Further, there is no single, standardized definition of MI which would extend across clinical-therapeutic settings (25). Still, MI is recognized as a focus of clinical concern, conceptually and clinically distinct from PTSD (26). One frequently cited definition of MI is that of "a deep sense of transgression including feelings of shame, grief, meaninglessness, and remorse from having violated core moral beliefs" (27). Such transgressions occur in the context of potentially morally injurious events (e.g., violence, human carnage, painful loss, feelings of betrayal by one's leaders) (2831). Compared to PTSD, the impact of MI on trust is thought to be much greater. Among those affected by MI, the capacity for trust is believed to be lost, impaired, or even destroyed $(29,32)$, leaving Veterans and Service members susceptible to an expectancy of harm, exploitation, and humiliation from others (33). No published prevalence estimates of MI are available, though combat Veterans have been found to have a high intensity of exposure to potentially morally injurious events (34). In some cases, PTSD and MI may also present as co-morbidities (26).

The aim of the present study is to examine and identify relationships linking general trust with select psychological, social, religious, and physical health outcomes in a mixed sample of Veterans and Service members in the United States. This study is unique in its use of a sample with a history of deployment to a combat zone as well as PTSD symptomatology. The present study adds to the extant literature by examining bivariate and multivariate relationships involving general trust, affording a more robust understanding of how trust stands to impact the health and well-being of Veterans and Service members with combat-related PTSD symptomatology. The findings could serve to inform future research aimed at developing interpersonal as well as organizational trust among combat Veterans and Service members, in addition to mitigating any adverse health effects resulting from having difficulty with general trust. 


\section{METHODOLOGY}

Participants for this cross-sectional study were recruited from six different sites. This included a sample of $n=373$ Veterans recruited from the Department of Veterans Affairs (VA) Medical Center (MC) in Durham ( $n=72$; North Carolina), VA Greater Los Angeles Healthcare System $(n=99$; California), Charlie Norwood VAMC ( $n=119$; Augusta, Georgia), Michael E. DeBakey VAMC ( $n=48$; Houston, Texas), Audie L. Murphy VAMC ( $n=35$; San Antonio, Texas). A sample of $n=54$ active duty Service members were recruited through Liberty University ( $n=54$; Lynchburg, Virginia). Only Veteran or active duty Service members, with a self-reported history of deployment to a combat theater, and exhibiting PTSD symptoms were included in this study.

The data analyzed here were drawn from a larger study examining the psychometric properties of a measure of moral injury. A detailed methodology of this larger study has been published elsewhere (35). In brief, after informed consent was obtained, paper questionnaires were completed in person at all sites except the Liberty University site where the questionnaire was completed online. Participants were compensated with a $\$ 25$ gift card for their time. This study was approved by the institutional review boards (IRBs) and Research \& Development (R\&D) Committees at Duke University as well as at each data collection site. The demographic, military, social, religious, psychological, and physical health characteristics of the sample are presented in Table $\mathbf{1}$.

We applied several procedural remedies in an effort to mitigate any potential for common method bias (36). As part of the informed consent process, the sample was duly informed that responses would not be applied for diagnostic purposes nor would responses come to bear on the Veteran's or the Service member's provision of health care services or other benefits. Further, all responses were provided anonymously. The survey packet included a variety of questions and instruments with instructions designed to preclude any issues related to question order or "socially desirable responses." Lastly, our measurements were in large part limited to high-quality empirically validated and published instruments which have already been extensively used in research.

\section{Measures}

\section{Demographic Characteristics}

Respondents were asked their age, gender, race, education, and marital status. Respondents were also asked their religious affiliation, with the following answer options: Christian, Jewish, Hindu, Muslim, Buddhist, other, no affiliation, and atheist/agnostic.

\section{General Trust}

The 6-item General Trust Scale (GTS) was used to assess beliefs about the honesty and trustworthiness of others (37). The GTS has been extensively used in studies examining general trust (38$40)$. The original validation study provided Cronbach's alpha $(\alpha)$ values of 0.72 in a sample of American college students, 0.78 in an American general population sample, 0.76 in a sample
TABLE 1 | Sample characteristics and bivariate associations between trust (GTS) and demographic, psychological, social, and physical health outcomes.

\begin{tabular}{|c|c|c|}
\hline & $\begin{array}{l}\text { Mean } \\
\text { (SD)/\% (n) }\end{array}$ & Trust ( $r$ or $t)$ \\
\hline \multicolumn{3}{|l|}{ DEMOGRAPHIC } \\
\hline Age, years & $53.6(14.7)$ & $r=0.25^{\star \star \star \star}$ \\
\hline Gender, \% male & $88.7(377)$ & $t=1.1$ \\
\hline Race, \% Caucasian & $39.2(165)$ & $t=2.0^{*}$ \\
\hline Education, years & $14.1(3.3)$ & $r=0.10^{\star}$ \\
\hline Marital status, \% married & $49.2(207)$ & $t=1.2$ \\
\hline \multicolumn{3}{|l|}{ MILITARY } \\
\hline Combat, \% involved & $69.3(293)$ & $t=0.5$ \\
\hline Combat theater, \% Middle East & $54.1(229)$ & $t=-3.6^{\star \star \star}$ \\
\hline Time since deployed, years & $23.0(18.2)$ & $r=0.16^{\star \star}$ \\
\hline \multicolumn{3}{|l|}{ SOCIAL } \\
\hline Relationship quality (range 1-10) & $6.4(2.6)$ & $r=0.39^{\star \star \star \star}$ \\
\hline Community involvement (range 1-10) & $3.9(2.6)$ & $r=0.32^{\star \star \star \star}$ \\
\hline \multicolumn{3}{|l|}{ RELIGIOUS } \\
\hline Christian affiliation, \% Christian & $82.8(351)$ & $t=-0.9$ \\
\hline Religious commitment (BIAC) (10-100) & $43.9(20.9)$ & $r=0.15^{\star \star}$ \\
\hline \multicolumn{3}{|l|}{ PSYCHOLOGICAL } \\
\hline PTSD diagnosis (self-reported; \% yes) & $81.3(340)$ & $t=-2.6^{\star}$ \\
\hline PTSD severity (PCL-5; 0-80) & $52.3(16.2)$ & $r=-0.20^{\star \star \star \star}$ \\
\hline Depressive symptoms (HADS; range 7-28) & $16.6(4.1)$ & $r=-0.36^{\star \star \star \star}$ \\
\hline Anxiety symptoms (HADS; range 7-28) & $19.5(4.1)$ & $r=-0.33^{\star \star \star \star}$ \\
\hline Alcohol use, \% more than 2 drinks/day & $11.1(47)$ & $t=0.2$ \\
\hline \multicolumn{3}{|l|}{ PHYSICAL } \\
\hline Pain severity (range 1-10) & $6.0(2.6)$ & $r=-0.08$ \\
\hline Physical impairment (range 1-10) & $5.7(2.8)$ & $r=-0.05$ \\
\hline
\end{tabular}

of Japanese students, and 0.70 in a Japanese general population sample. In the present sample, $\alpha=0.85$. This is the first known study to apply the GTS in a mixed sample of Veterans and active duty Service members. Factor structure and acrosssample correlations of factor loadings were generally high. For the purposes of the present study, GTS response categories were expanded from a 5-point to a 10-point Likert-type scale, yielding a total composite GTS score range of 6-60, with higher scores indicative of greater trust. Principle components factor analysis of the GTS in the present study demonstrated a single factor explaining $>90 \%$ of the variance in the GTS.

\section{PTSD}

The PTSD Checklist for DSM-5 (PCL-5) is a 20-item measure assessing for the symptoms required for a PTSD diagnosis per criteria outlined in the Diagnostic and Statistical Manual, Fifth Edition $(41,42)$. The PCL-5 has shown high reliability and strong associations with combat exposure and functional impairment in military personnel $(43,44)$. Scores on the PCL- 5 above a cutoff of 31-33 are reported to have the highest quality of efficiency in determining a DSM-5 diagnosis of PTSD (sensitivity of 0.88 , specificity of 0.69 , and positive predictive value of 0.81 ). In the 
present sample, $\alpha=0.94$. Participants were additionally asked if they had ever received a formal clinical diagnosis of PTSD (yes or no).

\section{Combat-Related Symptomatology}

All respondents self-reported either (a) deployment to a combat zone, without combat involvement or (b) deployment and combat involvement. For the purposes of the present study, this is taken to be indicative of combat-related symptomatology. A variety of deployment-related stressors have been associated with adverse mental health outcomes (45-47). Respondents were also asked their theater(s) of combat (e.g., Middle East, Vietnam, Korea, WWII, etc.) and the number of years since their last deployment.

\section{Depressive/Anxiety Symptomatology}

The 14-item Hospital Anxiety and Depression Scale (HADS) assesses for anxiety and depressive symptoms, each measured by seven items (48). The HADS has been reported to have high internal reliability ( $\alpha=0.85$ for the anxiety subscale, $\alpha=0.84$ for the depression subscale, and $\alpha=0.89$ for the overall scale) (49). In the present sample, $\alpha=0.86$.

\section{Alcohol Use}

Daily alcohol intake was measured using a single item on a 4point scale, ranging from "none" to "a lot (>6 drinks/day)". For the purposes of data analysis, responses were dichotomized into (a) $<2$ drinks/day and (b) $>2$ drinks/day.

\section{Social Involvement}

Respondents were asked to respond to two questions asking about (a) the quality of their relationships with spouse, children, and friends and (b) their level of involvement in community activities (other than religious group participation). Each was rated on a scale from 1 (not good/not at all) to 10 (very good/a great deal). The scores on the two items were summed to create a composite score ranging from 2 to 20 , where higher scores are indicative of greater social involvement. In the present sample, $\alpha=0.57$.

\section{Religiosity}

The 10-item Belief into Action Scale (BIAC) is used to assess religious involvement $(50,51)$. This measure assesses degree of religious commitment, time spent in religious activity, and money given for religious causes. Each item is scored on a scale from 1 to 10, yielding a composite score range of 10-100, with higher scores indicating greater religiosity. In the original validation study, the internal reliability $(\alpha=0.89,95 \% C I=$ $0.86-0.91$ ) and test-retest reliability for the BIAC (intra-class correlation or ICC $=0.92,95 \% C I=0.87-0.95$ ) were high. The scale has robust convergent, discriminant, and factor analytic validity (one factor explaining $94 \%$ of variance). In the present study, $\alpha=0.90$.

\section{Physical Health}

Difficulty engaging in physical activity level was assessed with a single item rated on a 0 to 10 scale $(0=$ no difficulty with physical activity, $10=$ great difficulty with physical activity). Current pain level was also assessed with a single question ("How much physical pain do you have on a daily basis?") likewise with ratings from 0 to $10(0=$ no pain, $10=$ severe pain $)$.

\section{Missing Values}

If more than $50 \%$ of responses were left unanswered on the GTS, then such individual cases were removed from data analysis by list-wise deletion. In cases of missing items, if participants answered at least $50 \%$ of items on a given scale, the average of items answered was substituted for the missing item value. Missing values had to be substituted in $2.4 \%$ of GTS cases (10 cases; nine involving a substitution of one item and one case involving two items), $9.9 \%$ of PCL-5 cases, $8.3 \%$ of HADS cases, $<0.5 \%$ of the social involvement questions, and $5.9 \%$ of BIAC cases.

\section{Statistical Analyses}

Means (standard deviations) and frequency distributions were calculated to describe the sample. Associations between trust (6-item GTS) and demographic, military, social, religious, psychological, and physical health characteristics were examined using Pearson correlations for bivariate analysis of continuous variables and the Student's $t$-test for comparison of trust scores across dichotomized categorical variables. Multivariate regression was used to examine the association between trust and mental, social-religious, and physical health states, controlling for demographic and military characteristics. First, all demographic and military characteristics were included in full multivariate models; second, only characteristics associated with the outcomes at $p<0.20$ were included in final reduced models. Statistical significance was set at $p<0.05$. SAS (version 9.3; SAS Institute Inc., Cary, North Carolina) was used for all analyses.

\section{RESULTS}

A total of $n=7(1.6 \%)$ individual cases were removed from data analysis owing to the omission of more than $50 \%$ of items on the GTS. The mean on the GTS was 35.1 (SD = 11.0) ranging from 6.0 to 54.0, with a median of 36.0 ( $n=$ 420). No significant difference on trust was found between Veterans and Active Duty Military on GTS scores (35.0, SD $=11.1$, vs. $35.5, S D=9.9$, respectively). Those who were older, white Caucasian, more educated, deployed to combat theaters other than the Middle East (i.e., Vietnam, etc.), and deployed longer ago, all had higher trust scores (Table 1). With regard to social interactions, Veterans and Active Duty Military who scored higher on the GTS reported greater community involvement and better relationships with family and friends, and were significantly more religious as well. Greater trust was also associated with a lower likelihood of self-reporting having received a formal PTSD diagnosis and less severe PTSD symptomatology $(r=-0.20, p<0.0001)$, as well as less depression and lower levels of anxiety (Figure 1). Trust was not associated with alcohol intake, nor was it significantly related to either daily pain severity or impairments in physical functioning. 


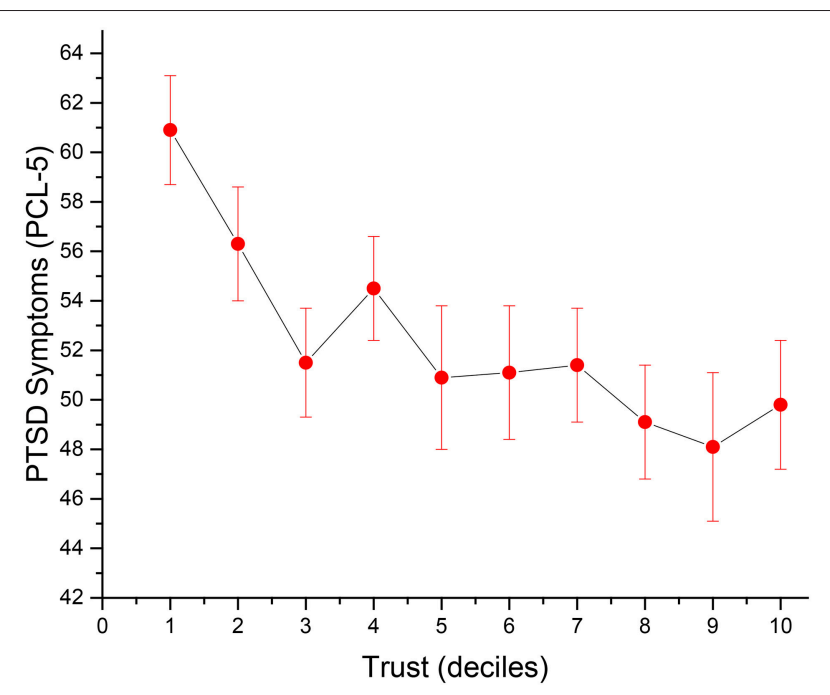

FIGURE 1 | Relationship between trust and PTSD symptoms (standard errors) (uncontrolled)

\section{Multivariate Analyses}

The relationships between trust and psychological, social, religious, and physical health were examined in multivariate regression models, controlling for demographic and military characteristics (Table 2).

\section{PTSD Symptomatology}

Among demographic and military factors in full models that included all of these characteristics, only two were related to PTSD symptom severity (at $p<0.20$ ). Being non-White (i.e., Black or Hispanic, primarily) was associated with greater PTSD severity, as was a history of deployment to the Middle East combat theater. When controlling for both of these factors, however, trust remained strongly and inversely associated with PTSD symptoms $(B=-0.27, S E=0.07, p=0.0002)$.

\section{Depressive Symptomatology}

In the full model, greater depressive symptoms were associated with less education, being married, not being Christian, and not being actively involved in combat. Reduced models controlling for these demographic and military factors indicated that greater trust remained inversely related to depressive symptoms and was the strongest of all correlates $(B=-0.14, S E=0.02$, $p<0.0001)$.

\section{Anxiety}

In the full model, greater anxiety was respectively reported by younger participants, married respondents, and those deployed to the Middle East. Controlling for these factors, greater trust remained inversely related to anxiety symptoms, and again, was the strongest and only significant inverse correlate $(B=-0.11$, $S E=0.02, p<0.0001)$.

\section{Social Interaction}

In the full model, social interaction was greater among those with more education, those who were actually involved in combat, and those who were not deployed to the Middle East (i.e., those indicating they served in Vietnam, Korea, World War II, or other theaters). Again, greater trust remained significantly related to, and was the strongest predictor for, greater social interaction, even after controlling for these factors $(B=0.15, S E=0.02$, $p<0.0001)$.

\section{Religiosity}

In the full model, those who were older, non-White, with more education, and Christian reported higher scores on religious involvement. After controlling for these factors in the reduced model, greater trust remained significantly correlated with greater religiosity $(B=0.24, S E=0.09, p=0.005)$.

\section{Physical Health}

Daily pain severity was related to older age and less education, most strongly in non-White race respondents, but was not related to level of trust in either the full model or the reduced model. Likewise, impairments in physical functioning were related to older age, less education, involvement in actual combat, most strongly in non-White race respondents, but was again unrelated to level of trust.

\section{DISCUSSION}

The aim of the present study was to examine the relationship between general trust and select health outcomes, controlling for potentially confounding variables, in a population of Veterans and Service members with combat-related PTSD symptomatology. Several significant relationships were identified, indicating an inverse relationship between trust and PTSD, depressive, and anxiety symptomatology. Greater levels of trust were also significantly associated with increased social interaction and religiosity. Lastly, no significant associations were identified with either physical functioning or pain level. To the best knowledge of the authors, these findings appear to be without precedent in the literature, underscoring a need for additional, hypothesis-driven research.

The present findings highlight how general trust is correlated with a variety of health outcomes in a sample of Veterans and Service members with combat-related PTSD symptomatology. As Service members continue to return from foreign theaters of combat and return back into the community as Veterans, developing understandings of the clinical importance of general trust will no doubt remain a focus of empirical attention. Irrespective of clinical condition, enhanced or diminished trust among Veterans and Service members has also been found to impact such domains as suicide risk screenings (52), employment (53), relationships (54), and psychosocial readjustment (55-57). Future research should invariably include a focus on identifying viable options and avenues for facilitating trust among those affected by combat-related PTSD symptomatology. At present, (re)establishing the capacity to trust is described as a secondary outcome of existing PTSD treatment options, with cognitive behavioral therapy being the most promising treatment for facilitating general trust (58-60). 
TABLE 2 | Multivariate associations between trust, psychological, social, and physical health outcomes.

\begin{tabular}{|c|c|c|c|c|c|c|c|}
\hline & $\begin{array}{l}\text { PTSD } \\
B \text { (SE) }\end{array}$ & $\begin{array}{c}\text { Depression } \\
\text { B (SE) }\end{array}$ & $\begin{array}{c}\text { Anxiety } \\
B \text { (SE) }\end{array}$ & $\begin{array}{l}\text { Social } \\
B(S E)\end{array}$ & $\begin{array}{c}\text { Religiosity } \\
\text { B (SE) }\end{array}$ & $\begin{array}{l}\text { Pain } \\
B \text { (SE) }\end{array}$ & $\begin{array}{c}\text { Physical } \\
\text { functioning } \\
B(S E)\end{array}$ \\
\hline Age, years & - & - & $-0.04(0.02)$ & - & $0.04(0.07)$ & $0.03(0.01)^{\star \star \star}$ & $0.03(0.01)^{\star \star}$ \\
\hline Gender, female & - & - & - & - & - & - & - \\
\hline Race, Caucasian & $-5.85(1.58)^{\star \star \star}$ & - & - & - & $-5.92(1.94)^{\star \star}$ & $-1.19(0.26)^{\star \star \star \star}$ & $-1.06(0.28)^{\star \star \star}$ \\
\hline Education, years & - & $-0.12(0.06)^{\star}$ & - & $0.15(0.06)^{*}$ & $0.82(0.29)^{\star \star}$ & $-0.06(0.04)$ & $-0.07(0.04)$ \\
\hline Marital status, married & - & $1.08(0.38)^{\star \star}$ & $0.69(0.38)$ & - & - & - & - \\
\hline Christian (yes) & - & $-0.59(0.49)$ & - & - & $18.9(2.5)^{\star \star \star \star}$ & - & - \\
\hline Combat involved (yes) & - & $-0.75(0.40)$ & - & $1.14(0.42)^{\star \star}$ & - & - & $0.41(0.29)$ \\
\hline Combat theater (ME) & $0.32(1.57)$ & - & $0.37(0.58)$ & $-0.87(0.40)^{*}$ & - & - & - \\
\hline Time since deployed (years) & - & - & - & - & - & - & - \\
\hline Trust (6-item GTS) & $-0.27(0.07)^{\star \star \star}$ & $-0.14(0.02)^{\star \star \star \star}$ & $-0.11(0.02)^{\star \star \star \star}$ & $0.15(0.02)^{\star \star \star \star}$ & $0.25(0.09)^{\star \star}$ & $-0.02(0.01)$ & $-0.01(0.01)$ \\
\hline Model R-square (n) & $0.07^{\star \star \star \star}(410)$ & $0.17^{\star \star \star \star}(403)$ & $0.14^{\star \star \star \star}(409)$ & $0.20^{\star \star \star \star}(404)$ & $0.18^{\star \star \star \star}(407)$ & $0.10^{\star \star \star \star}(410)$ & $0.07^{\star \star \star \star}(407)$ \\
\hline
\end{tabular}

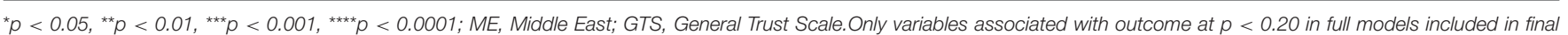
models above.

In the present sample, greater levels of trust were associated with both increased social interaction and greater religiosity. The implications of this finding potentially extend beyond combatrelated PTSD symptomatology and may also serve to inform an emerging body of research into MI. For example, issues related to religion and spirituality have been posited as potential "root causes" of MI $(25,61)$. The negative affect encapsulated by MI may draw from faith-based standards of moral conduct violated in the course of a morally injurious event. Through social interaction (e.g., religious practice), those affected by MI are exposed to different sources of social capital that might help them rebuild trust (62). In the cases of both PTSD as well as MI, higher levels of trust intuitively suggest a salutary cycle of support, such as a propensity to engage with different sources of support, reinforcing and developing existing general trust, ultimately supporting favorable therapeutic outcomes.

Trust is dependent on a variety of factors. One might reasonably argue that some Veterans may have also had trust issues preceding their military service. For this reason, future research should also be guided by longitudinal data, including such variables as history of relationships with family of origin, any experiences of abandonment (e.g., "broken home," foster care), relationships with significant others, and marital history. It is not uncommon for Veterans to have difficult pre-military family experiences (63). Enlistment in the military services may, in some cases, be motivated by the desire for an alternative, more trustworthy "family experience" (64). In the United States, the issue of qualifying for Department of Veterans Affairs (VA) benefits also stands to tangibly impact general trust in this organization, with implications extending far beyond just populations affected by combat-related PTSD. In recent years, trust between Veterans and the VA health care system has been complicated by organizational issues and challenges (65-67). Another avenue for future research might include comparatively examining levels of general trust, inclusive of any associated health effects, among Veterans who have qualified for VA services vs. those who did not qualify.
The generalizability of the findings reported here and their interpretation is limited by several factors. This was a sample of convenience that involved volunteers who agreed to participate. As a cross-sectional study, it was impossible to determine causality (e.g., whether greater trust led to less PTSD, depression, anxiety, and better social relationships, or vice versa). Participants were recruited from sites located primarily in the southern United States, so these results may not apply to Veterans and/or Service members more generally, nor do they take into consideration certain regional, cultural, or contextual influences which may not be present in other parts of the country. Future research should consider diversifying sample recruitment across multiple military, civilian, and geographic regions/settings. The dynamic governing trust among Service members is presumably different from that of Veterans. Any such bias would have been mitigated by the inclusion of only a small subsample of active duty Service members $(n=54 ; 13 \%$ of the sample). The present study did not assess for different types of trauma experienced by the sample. Lastly, all data was self-reported and not verified by official government and/or clinical records.

Notwithstanding these limitations, the findings of this crosssectional study provide an important degree of insight into the association between general trust and select health outcomes in a sample of Veterans and Service members with PTSD symptomatology. Understandings of how trust impacts health outcomes remain limited. Further, a paucity of evidence-based support options exist for building trust $(68,69)$. By drawing attention to the possibility that increasing trust may lead to more favorable health outcomes, the intention was to inform future research into trust-building clinical interventions. The strength of these findings is reinforced by the use of a large, multisite sample inclusive of both Veterans and Service members with PTSD symptomatology, the use of psychometrically validated measures, and the careful assessment and control for numerous demographic and military characteristics. Future research should consider longitudinal studies of trust and health outcomes, developing comparative studies between combat- and 
non-combat-related PTSD, and seeking to better understand the role of faith in the development of trust.

\section{CONCLUSION}

This cross-sectional study sought to examine the relationship between general trust and select health outcomes in a mixed sample of Veterans and Service members with PTSD symptomatology. The findings suggest that trust is correlated with a variety of health outcomes in this group. Several significant relationships were identified between trust and clinical symptomatology of PTSD, depression, and anxiety, respectively. Trust was also associated with social interaction and religiosity. The findings suggest several avenues for additional research into how disturbed general trust impacts the health of Veterans and Service members with PTSD.

\section{ETHICS STATEMENT}

This study was conducted in accordance with IRB and R\&D Committee approval at Duke University as well as each data

\section{REFERENCES}

1. McKnight DH, Chervany NL. Trust and distrust definitions: one bite at a time. In: Falcone R, Singh M, Tan YH, (editors). Trust in Cyber-Societies. Berlin: Springer-Verlag (2001). p. 27-54.

2. DeNeve KM, Cooper H. The happy personality: a metaanalysis of 137 personality traits and subjective well-being. Psychol Bull. (1998) 124:197-229. doi: 10.1037/0033-2909.124. 2.197

3. Ratcliffe M, Ruddell M, Smith B. What is a "sense of foreshortened future?" a phenomenological study of trauma, trust, and time. Front Psychol. (2014) 5:1026. doi: 10.3389/fpsyg.2014.01026

4. Gray JG. The Warriors: Reflection on Men in Battle. Lincoln: Bison Books (1959/1998).

5. Owens GP, Steger MF, Whitesell AA, Herrera CJ. Posttraumatic stress disorder, guilt, depression, and meaning in life among military veterans. $J$ Trauma Stress (2009) 22:654-7. doi: 10.1002/jts.20460

6. Tick E. War and the Soul: Healing our Nation's Veterans from Post-Traumatic Stress Disorder. Wheaton, IL: Quest Books (2005).

7. Human Dimension Capabilities Development Task Force, Capabilities Development Integration Directorate, Mission Command Center of Excellence. Building Mutual Trust Between Soldiers and Leaders (2015). Available online at: https://usacac.army.mil/sites/default/files/publications/ HDCDTF_White\%20Paper_Building\%20Mutual\%20Trust\%20Between $\% 20$ Soldiers\%20and\%20Leaders_Final_2015_01_09_0.pdf

8. Allen CD, Braun WG. Trust, Implications for the Army Profession. Military Review (2013). Available online at: http://www.armyupress.army.mil/Portals/ 7/military-review/Archives/English/MilitaryReview_20131031_art012.pdf

9. Williams W, Graham DP, McCurry K, Sanders A, Eiseman J, Chiu PH, et al. Group psychotherapy's impact on trust in veterans with PTSD: a pilot study. Bull Menninger Clin. (2014) 78:335-48. doi: 10.1521/bumc.2014.78. 4.335

10. Callahan DJ. Combat-related mental health disorders: the case for resiliency in the long war. J Am Osteopath Assoc. (2010) 110:520-7. Available online at: http://jaoa.org/article.aspx?articleid=2094033

11. Maguen S, Luxton DD, Skopp NA, Gahm GA, Reger MA, Metzler TJ, et al. Killing in combat, mental health symptoms, and suicidal ideation in Iraq war veterans. J Anxiety Disord. (2011) 25:563-7. doi: 10.1016/j.janxdis.2011. 01.003 collection site. Prior to taking part, all participants gave written informed consent in accordance with the latest version of the Declaration of Helsinki.

\section{AUTHOR CONTRIBUTIONS}

MK, DA, and HK: Contributed to writing article. HK: Data collection, database maintenance, data analysis.

\section{ACKNOWLEDGMENTS}

The views expressed are those of the authors and do not reflect the official policy or position of the Department of Veterans Affairs or the U.S. Government. None of the authors voice any conflicts of interest related to the conduct of this research activity. Institutional support for this work was provided by the VISN 2 Center of Excellence for Suicide Prevention (Canandaigua, New York), Duke University Medical Center (Durham, North Carolina), and VA Greater Los Angeles Healthcare System (Los Angeles, California).

12. Spelman JF, Hunt SC, Seal KH, Burgo-Black AL. Post deployment care for returning combat veterans. J Gen Intern Med. (2012) 27:1200-9. doi: 10.1007/s11606-012-2061-1

13. Charuvastra A, Cloitre M. Social bonds and posttraumatic stress disorder. Annu Rev Psychol. (2008) 59:301-28. doi: 10.1146/annurev.psych.58.110405. 085650

14. Zubriggen EL, Gobin RL, Kaehler LA. Trauma, attachment, and intimate relationships. J Trauma Dissoc. (2012) 13(2):127-33. doi: 10.1080/15299 732.2012 .642762

15. O’Toole TP, Johnson EE, Redihan S, Borgia M, Rose J. Needing primary care but not getting it: the role of trust, stigma and organizational obstacles reported by homeless veterans. J Health Care Poor Underserved (2015) 26:1019-31. doi: 10.1353/hpu.2015.0077

16. Hoge C. Interventions for war-related posttraumatic stress disorder: meeting veterans where they are. JAMA (2011) 306:549-51. doi: 10.1001/jama.2011.1096

17. Elliott L, Golub A, Bennett A, Guarino H. PTSD and cannabis-related coping among recent veterans in New York City. Contemp Drug Probl. (2015) 42:60-76. doi: 10.1177/0091450915570309

18. Sayer NA, Noorbaloochi S, Frazier P, Carlson K, Gravely A, Murdoch M. Reintegration problems and treatment interests among Iraq and Afghanistan combat veterans receiving VA medical care. Psychiatr Serv. (2010) 61:589-97. doi: 10.1176/ps.2010.61.6.589

19. Monson CM, Taft CT, Fredman SJ. Military-related PTSD and intimate relationships: from description to theory-driven research and intervention development. Clin Psychol Rev. (2009) 29:707-14. doi: 10.1016/j.cpr.2009.09.002

20. Breuninger MM, Teng EJ. Safe and secure: spiritually enhanced cognitive processing therapy for veterans with posttraumatic stress disorder. Spiritual Clin Pract. (2017) 4:262-73. doi: 10.1037/scp0000142

21. Iribarren J, Prolo P, Neagos N, Chiappelli F. Post-traumatic stress disorder: evidence-based research for the third millennium. Evid Based Complement Alternat Med. (2005) 2:503-12. doi: 10.1093/ecam/neh127

22. Committee on the Assessment of Ongoing Efforts in the Treatment of Posttraumatic Stress Disorder, Board on the Health of Select Populations, Institute of Medicine. Research on PTSD. In: Treatment for Posttraumatic Stress Disorder in Military and Veteran Populations: Final Assessment. Washington, DC: National Academies Press (2014). p. 175-213. 
23. Gates MA, Holowka DW, Vasterling JJ, Keane TM, Marx BP, Rosen RC. Posttraumatic stress disorder in veterans and military personnel: epidemiology, screening, and case recognition. Psychol Serv. (2012) 9:361-82. doi: $10.1037 / \mathrm{a} 0027649$

24. Richardson LK, Frueh BC, Acierno R. Prevalence estimates of combat-related post-traumatic stress disorder: critical review. Aust N Z J Psychiatry (2010) 44:4-19. doi: 10.3109/00048670903393597

25. Carey LB, Hodgson TJ, Krikheli L, Soh RY, Armour AR, Singh TK, Impiombato CG. Moral injury, spiritual care and the role of chaplains: an exploratory scoping review of literature and resources. J Relig Health (2016) 55:1218-45. doi: 10.1007/s10943-016-0231-x

26. Bryan CJ, Bryan AO, Roberge E, Leifker FR, Rozek DC. Moral injury, posttraumatic stress disorder, and suicidal behavior among national guard personnel. Psychol Trauma (2018) 10:36-45. doi: 10.1037/tra0000290

27. Brock RN, Lettini G. Soul Repair: Recovering from Moral Injury After War. Boston, MA: Beacon Press (2012).

28. Currier JM, Holland JM, Drescher K, Foy D. Initial psychometric evaluation of the moral injury questionnaire - military version. Clin Psychol Psychother. (2015) 22:54-63. doi: 10.1002/cpp.1866

29. Litz BT, Stein N, Delaney E, Lebowitz L, Nash WP, Silva C, et al. Moral injury and moral repair in war veterans: a preliminary model and intervention strategy. Clin Psychol Rev. (2009) 29:695-706. doi: 10.1016/j.cpr.2009.07.003

30. Nash WP, Carper TLM, Mills MA, Au T, Goldsmith A, Litz BT. Psychometric evaluation of the moral injury events scale. Mil Med. (2013) 178:646-52. doi: 10.7205/MILMED-D-13-00017

31. Stein NR, Mills MA, Arditte K, Mendoza C, Borah AM, Resick $\mathrm{PA}$, et al. A scheme for categorizing traumatic military events. Behav Modif. (2012) 36:787-807. doi: 10.1177/01454455124 46945

32. Meador KG, Cantrell WC, Nieuwsma J. Recovering from moral injury. In: Kruschwitz RB, (editors). Patterns of Violence. Waco, TX: The Institute for Faith and Learning (2016). p. 35-42.

33. Shay J. Moral injury. Psychoanal Psychol. (2014) 31:182-91. doi: $10.1037 / \mathrm{a} 0036090$

34. Wisco BE, Marx BP, May CL, Martini B, Krystal JH, Southwick SM, et al. Moral injury in U.S. combat veterans: results from the national health and resilience in veterans study. Depress Anxiety (2017) 34:340-7. doi: 10.1002/ da. 22614

35. Koenig HG, Ames D, Youssef N, Oliver JP, Volk F, Teng EJ, et al. The moral injury symptom scale - military version. J Relig Health (2018) 57:249-65. doi: 10.1007/s10943-017-0531-9

36. Podsakoff PM, MacKenzie SB, Lee JY, Podsakoff NP. Common method biases in behavioral research: a critical review of the literature and recommended remedies. J Appl Psychol. (2003) 88:879-903. doi: 10.1037/0021-9010. 88.5 .879

37. Yamagishi T, Yamagishi M. Trust and commitment in the United States and Japan. Motiv Emotion (1994) 18:129-66. doi: 10.1007/BF02249397

38. Yamagishi T. The provisioning of a sanctioning system as a public good. J Pers Soc Psychol. (1986) 51:110-6. doi: 10.1037/0022-3514.51.1.110

39. Levi M, Stoker L. Political trust and trustworthiness. Annu Rev Polit Sci. (2000) 3:475-507. doi: 10.1146/annurev.polisci.3.1.475

40. Kramer RM. Trust and distrust in organizations: emerging perspectives, enduring questions. Annu Rev Psychol. (1999) 50:569-98. doi: 10.1146/annurev.psych.50.1.569

41. Bovin MJ, Marx BP, Weathers FW, Gallagher MW, Rodriguez P, Schnurr PP, et al. Psychometric properties of the PTSD checklist for diagnostic and statistical manual of mental disorders-fifth edition (PCL-5) in veterans. Psychol Assess. (2016) 28:1379-91. doi: 10.1037/pas0000254

42. American Psychiatric Association (ed). Diagnostic and Statistical Manual of Mental Disorders, 4th Edn. Arlington, TX: American Psychiatric Association (2013).

43. Hoge CW, Riviere LA, Wilk JE, Herrell RK, Weathers FW. The prevalence of post-traumatic stress disorder (PTSD) in US combat soldiers: a head-to-head comparison of DSM-5 versus DSM-IV-TR symptom criteria with the PTSD checklist. Lancet Psychiat. (2014) 1:269-77. doi: 10.1016/S2215-0366(14)70235-4

44. Ashbaugh AR, Houle-Johnson S, Herbert C, El-Hage W, Brunet A. Psychometric validation of the english and french versions of the posttraumatic stress disorder checklist for DSM-5 (PCL-5). PLoS ONE (2016) 11:e0161645. doi: 10.1371/journal.pone.0161645

45. Pietrzak E, Pullman S, Cotea C, Nasveld P. Effects of deployment on mental health in modern military forces: a review of longitudinal studies. J Mil Veterans Health (2012) 21:24-36. Available online at: https://jmvh.org/article/ effects-of-deployment-on-health-behaviours-in-military-forces-a-reviewof-longitudinal-studies/

46. Yehuda R, Vermetten E, McFarlane AC, Lehrner A. PTSD in the military: special considerations for understanding prevalence, pathophysiology and treatment following deployment. Eur J Psychotraumatol. (2014) 5:25322. doi: 10.3402/ejpt.v5.25322

47. Xue C, Ge Y, Tang B, Liu Y, Kang P, Wang M, Zhang L. A meta-analysis of risk factors for combat-related PTSD among military personnel and veterans. PLoS ONE (2015) 10:e0120270. doi: 10.1371/journal.pone.0120270

48. Zigmond AS, Snaith RP. The hospital anxiety and depression scale. Acta Psychiatr Scand. (1983) 67:361-70. doi: 10.1111/j.1600-0447.1983. tb09716.x

49. Gough K, Hudson P. Psychometric properties of the hospital anxiety and depression scale in family caregivers of palliative care patients. J Pain Symptom Manage. (2009) 37:797-806. doi: 10.1016/j.jpainsymman.2008.04.012

50. Koenig HG, Nelson B, Shaw SF, Al Zaben F, Wang Z, Saxena S. Belief into Action scale: a brief but comprehensive measure of religious commitment. Open J Psychiatry (2015) 5:66-77. doi: 10.4236/ojpsych.2015.51010

51. Koenig HG, Wang Z, Al Zaben F, Adi A. Belief into Action Scale: a comprehensive and sensitive measure of religious involvement. Religions (2015) 6:1006-16. doi: 10.3390/rel6031006

52. Ganzini L, Denneson LM, Press N, Bair MJ, Helmer DA, Poat J, et al. Trust is the basis for effective suicide risk screening and assessment in veterans. J Gen Intern Med. (2013) 28:1215-21. doi: 10.1007/s11606-013-2412-6

53. Griffith J. Homecoming of soldiers who are citizens: re-employment and financial status of returning army national guard soldiers from operations Iraqi freedom (OIF) and enduring freedom (OEF). Work (2015) 50:85-96. doi: 10.3233/WOR-131794

54. Melvin KC, Wenzel J, Jennings BM. Strong army couples: a case study of rekindling marriage after combat deployment. Res Nurs Health (2015) 38:7-18. doi: $10.1002 /$ nur.21630

55. Stretch RH. Psychosocial readjustment of Canadian Vietnam veterans. J Consult Clin Psychol. (1991) 59:188-9. doi: 10.1037/0022-006X.59.1.188

56. Thomas VJ, Bowie SL. Sense of community: is it a protective factor for military veterans? J Soc Serv Res. (2016) 42:313-31. doi: 10.1080/01488376.2015.1109575

57. Demers A. When veterans return: the role of community in reintegration. J Loss Trauma (2011) 16:160-79. doi: 10.1080/15325024.2010. 519281

58. Swan S, Keen N, Reynolds N, Onwumere J. Psychological interventions for post-traumatic stress symptoms in psychosis: a systematic review of outcomes. Front Psychol. (2017) 8:341. doi: 10.3389/fpsyg.2017.00341

59. Guidelines development panel for the treatment of posttraumatic stress disorder in adults. Clinical Practice Guideline for the Treatment of PTSD. Washington, DC: American Psychological Association. (2017).

60. Purvis KB, Cross DR, Dansereau DF, Parris SR. Trust-based relational intervention (TBRI): a systemic approach to complex developmental trauma. Child Youth Serv. (2013) 34:360-86. doi: 10.1080/0145935X.2013.859906

61. Kopacz MS, Connery AL, Bishop TM, Bryan CJ, Drescher KD, Currier JM, et al. Moral injury: a new challenge for complementary and alternative medicine. Complement Ther Med. (2016) 24:29-33. doi: 10.1016/j.ctim.2015.11.003

62. Kopacz MS, Morley SW, Wozniak BM, Simons KV, Bishop TM, Vance CG. Religious well-being and suicide ideation in veterans - an exploratory study. Pastoral Psychol. (2016) 65:481-91. doi: 10.1007/s11089-016-0 699-z

63. Friedman MJ, Schnurr PP, McDonagh-Coyle A. Post-traumatic stress disorder in the military veteran. Psychiatr Clin North Am. (1994) 17:265-77. doi: 10.1016/S0193-953X(18)30113-8

64. Mankowski M, Tower LE, Brandt CA, Mattocks K. Why women join the military: enlistment decisions and postdeployment experiences of service members and veterans. Soc Work (2015) 60:315-23. doi: 10.1093/sw/swv035

65. Kizer KW, Jha AK. Restoring trust in VA health care. N Engl J Med. (2014) 371:295-7. doi: 10.1056/NEJMp1406852 
66. Shulkin DJ. Beyond the VA crisis - becoming a high-performance network. $N$ Engl J Med. (2016) 374:1003-5. doi: 10.1056/NEJMp1600307

67. Williams JW, Jackson GL. Utilizing evidence to address the health and health care needs of veterans. N C Med J. (2015) 76:294-8. doi: $10.18043 / \mathrm{ncm} \cdot 76.5 .294$

68. Kransner BR, Joyce AJ. Truth, trust, and relationships: Healing Interventions in Contextual Therapy. New York, NY: Brunner/Mazel. (1995).

69. Beukers E, Bertolini L, Brömmelstroet M. An assessment of interventions for improving communication and trust in cost benefit analysis processes. Impact Assess Proj A (2015) 33:28-42. doi: 10.1080/14615517.2014. 941142
Conflict of Interest Statement: The authors declare that the research was conducted in the absence of any commercial or financial relationships that could be construed as a potential conflict of interest.

Copyright () 2018 Kopacz, Ames and Koenig. This is an open-access article distributed under the terms of the Creative Commons Attribution License (CC BY). The use, distribution or reproduction in other forums is permitted, provided the original author(s) and the copyright owner(s) are credited and that the original publication in this journal is cited, in accordance with accepted academic practice. No use, distribution or reproduction is permitted which does not comply with these terms. 